\title{
The arrival, establishment and spread of a highly virulent Edwardsiella ictaluri strain in farmed tilapia, Oreochr omis spp.
}

\author{
Doan Thi Nhinh ${ }^{1}$, Nguyen Thi Huong Giang ${ }^{1}$, Kim Van Van ${ }^{1}$, Lua Thi Dang ${ }^{2}$, Ha Dong ${ }^{3}$, \\ and Truong Dinh Hoai ${ }^{1}$
}

${ }^{1}$ Vietnam National University of Agriculture

${ }^{2}$ Research Institute for Aquaculture No 1 Bac Ninh 16352 Vietnam

${ }^{3}$ Asian Institute of Technology

November 7, 2021

\begin{abstract}
Edwardsiella ictaluri is an emerging bacterial pathogen that affects farmed tilapia ( Oreochromis spp.). This study reports the arrival, establishment, and widespread findings of E. ictaluri in farmed tilapia in Vietnam. Among 26 disease outbreaks from 9 provinces in Northern Vietnam during 2019-2021, 19 outbreaks originated from imported seeds, while outbreaks in seven farms were from domestic sources. Clinically sick fish showed the appearance of numerous white spots in visceral organs, and accumulative mortality reached $30 \%-65 \%$. Twenty-six representative bacterial isolates recovered from 26 disease outbreaks were identified as E. ictaluri based on a combination of phenotypic tests, genus- and species-specific polymerase chain reaction assays, $16 S r R N A$ and $\operatorname{gyr} B$ sequencing, and phylogenetic analysis. All isolates harbored the same virulence gene profiles esrC ${ }^{+}, \operatorname{evp} C^{+}$, ure $A-C^{+}$, eseI $I^{-}$esc $D^{-}$, and $\operatorname{vir} D 4^{-}$. Antimicrobial susceptibility tests revealed that $80.8 \%-100 \%$ of isolates were multidrug resistant, with resistance to $4-8$ antimicrobials in the groups of penicillin, macrolides, sulfonamides, amphenicols, and glycopeptides. The experimental challenge successfully induced disease that mimicked natural infection. The median lethal doses $(\mathrm{LD} 50)$ of the tested isolates $(\mathrm{n}=4)$ were $42-61$ colony forming units/fish, indicating their extremely high virulence. This emerging pathogen is established and has spread to various geographical locations, causing serious impacts on farmed tilapia in northern Vietnam. It is likely that this pathogen will continue to spread through contaminated stocks (both imported and domestic sources) and persist. Thus, increased awareness, combined with biosecurity measures and emergent vaccination programs is essential to mitigate the negative impact of this emerging disease on the tilapia farming industry.
\end{abstract}

\section{Original article}

The arrival, establishment and spread of a highly virulent Edwardsiella ictaluri strain in farmed tilapia, Oreochromis spp.

Doan Thi Nhinh ${ }^{1,3}$, Nguyen Thi Huong Giang ${ }^{2}$, Kim Van Van ${ }^{1}$, Lua Thi Dang ${ }^{3}$, Ha Thanh Dong ${ }^{4}$, Truong Dinh Hoai ${ }^{1 *}$

${ }^{1}$ Faculty of Fisheries, Vietnam National University of Agriculture, Hanoi 131004, Vietnam

${ }^{2}$ Faculty of Veterinary Medicine, Vietnam National University of Agriculture, Hanoi 131004, Vietnam

${ }^{3}$ Research Institute for Aquaculture No 1, Bac Ninh 16352, Vietnam

${ }^{4}$ Department of Food, Agriculture and Bioresources, School of Environment, Resources 83 Development (SERD), Asian Institute of Technology (AIT), Klong Luang, Pathumthani, Thailand

\section{Corresponding author:}


Truong Dinh Hoai, Faculty of Fisheries, Vietnam National University of Agriculture, Hanoi, Vietnam

Email: tdhoai@vnua.edu.vn

ORCID: https://orcid.org/0000-0002-2271-849X

\section{SUMMARY}

Edwardsiella ictaluri is an emerging bacterial pathogen that affects farmed tilapia (Oreochromis spp.). This study reports the arrival, establishment, and widespread findings of E. ictaluri in farmed tilapia in Vietnam. Among 26 disease outbreaks from 9 provinces in Northern Vietnam during 2019-2021, 19 outbreaks originated from imported seeds, while outbreaks in seven farms were from domestic sources. Clinically sick fish showed the appearance of numerous white spots in visceral organs, and accumulative mortality reached $30 \%-65 \%$. Twenty-six representative bacterial isolates recovered from 26 disease outbreaks were identified as E. ictaluri based on a combination of phenotypic tests, genus- and species-specific polymerase chain reaction assays, $16 \mathrm{~S}$ $r R N A$ and $g y r B$ sequencing, and phylogenetic analysis. All isolates harbored the same virulence gene profiles

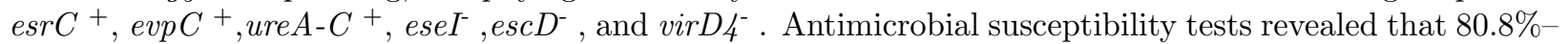
$100 \%$ of isolates were multidrug resistant, with resistance to $4-8$ antimicrobials in the groups of penicillin, macrolides, sulfonamides, amphenicols, and glycopeptides. The experimental challenge successfully induced disease that mimicked natural infection. The median lethal doses $\left(\mathrm{LD}_{50}\right)$ of the tested isolates $(\mathrm{n}=4)$ were 42-61 colony forming units/fish, indicating their extremely high virulence. This emerging pathogen is established and has spread to various geographical locations, causing serious impacts on farmed tilapia in northern Vietnam. It is likely that this pathogen will continue to spread through contaminated stocks (both imported and domestic sources) and persist. Thus, increased awareness, combined with biosecurity measures and emergent vaccination programs is essential to mitigate the negative impact of this emerging disease on the tilapia farming industry.

Keywords : Edwardsiella ictaluri, outbreaks, tilapia, virulence genes, antimicrobial resistance

\section{INTRODUCTION}

Interest in tilapia is increasing in aquaculture because the species is affordable to grow and maintain, is an inexpensive source of protein and nutrients, and has high tolerance to stress induced by handling, highdensity conditions, and a wide range of environmental conditions (Prabu et al., 2019). To date, tilapia, which has been farmed in over 135 countries, is the second most important farmed fish worldwide (FAO, 2018; Prabu et al., 2019). In 2015, global tilapia production was 6.4 million tons, with an estimated value of $\$ 9.8$ billion and a trade value of $\$ 1.8$ billion (FAO, 2017). Vietnam is among the top seven tilapia producers worldwide (FAO, 2017). The yield of tilapia in Vietnam reached 255,000 tons in 2018, and its production aims to reach 400,000 tons by 2030 (MARD, 2019). Intensive production and growing numbers of tilapia farms have led to the emergence and rapid spread of infectious diseases, which is likely to have a significant impact on overall tilapia production (Li et al., 2015; Romero et al., 2012).

Edwardsiella ictaluri a gram-negative rod-shaped bacterium belonging to the family Enterobacteriaceae, is the causative pathogen of enteric septicemia in channel catfish (ESC) in the United States (USA) (Hawke et al., 1981). The bacterium is a facultative intracellular pathogen that survives inside channel catfish phagocytes, such as macrophages and neutrophils (Baldwin \& Newton, 1993; Waterstrat et al., 1991). To date, the pathogen has been reported to infect other catfish species, including walking catfish and hybrid catfish in Thailand (Kasornchandra et al., 1987; Suanyuk et al., 2014), striped catfish in Vietnam, Indonesia, and Thailand (Dong et al., 2015; Rogge et al., 2013; Yuasa et al., 2003), yellow catfish in China (Liu et al., 2010) and non-catfish species, including zebrafish in the USA (Hawke et al., 2013), tilapia in the USA (Soto et al., 2012), and wild ayu in Japan (Hassan et al., 2012; Sakai et al., 2008). Naturally, disease outbreaks cause 40\%-90\% mortality (Dong et al., 2019; Dung et al., 2004; Iwanowicz et al., 2006), while experimental infection results in up to $100 \%$ mortality (Dong et al., 2019; Ngoc Phuoc et al., 2020; Plumb \& Sanchez, 1983; Sakai et al., 2008), indicating that E. ictaluriis a deadly pathogen in multiple freshwater fish species.

The Vietnamese catfish industry has suffered from Edwardsiellosis caused by E. ictaluri for almost two 
decades (Ferguson et al., 2001). The emergence of natural cases of E. ictaluri in red tilapia in open floating cages in northern Vietnam in 2016 raised alarm for the widespread appearance of this emerging pathogen in this significantly important industry (Dong et al., 2019). A recent comparative genomic analysis of E. ictaluri from different fish hosts revealed four distinct host-specific genotypes, indicating that the E. ictaluristrain from tilapia is an emerging, unique genotype (Machimbirike et al., 2021). However, little is known regarding the arrival, establishment, and spread of this E. ictaluri strain in the tilapia aquaculture industry in Vietnam. This study provides comprehensive information on the establishment and spread of a highly pathogenic $E$. ictaluri strain in northern Vietnam and highlights the importance of biosecurity measures, especially for imported stocks, to prevent the spread of this emerging pathogen.

\section{MATERIALS AND METHODS}

\subsection{Disease outbreaks, sampling, and bacterial isolation}

After the first report of E. ictaluri infection in red tilapia (Oreochromis sp.) in a northern province of Vietnam (Dong et al., 2019), similar disease outbreaks with massive mortalities continually occurred in various tilapia farms in nine provinces in northern Vietnam between February 2019 and March 2021. Epidemiological investigations and fish sampling were conducted at 26 affected farms (Table 1), including 5 earth-pond farms and 21 cage-culture farms located in 9 provinces in northern Vietnam (Figure 1).

During the study, information on the source of fish stocking (imported or domestic) and the estimation of fish mortality caused by E. ictaluri was obtained by interviewing the farmers. In each affected farm, the water temperature was measured at the time of fish sampling using a water quality meter (YSI Professional Plus, YSI Incorporated, Ohio, USA). Ten to fifteen diseased fish were collected, placed in sterile sealed plastic bags, and transferred to the laboratory of the Department of Aquatic Environment and Fish Pathology, Faculty of Fisheries, Vietnam National University of Agriculture (VNUA) in a cold box (below $4{ }^{\circ} \mathrm{C}$ ) for microbial analysis. The clinical signs and gross features of all the diseased fish were observed and recorded.

Bacteria were isolated from the head kidney, spleen, and liver of the affected fish using brain heart infusion agar (BHIA). The plates were then incubated at $28^{\circ} \mathrm{C}$ for $48 \mathrm{~h}$. Twenty-six representative isolates corresponding to 26 disease outbreaks were selected and preserved in brain heart infusion broth (BHIB) containing $20 \%$ glycerol and kept at $-80{ }^{\circ} \mathrm{C}$ for further examination.

\subsection{Biochemical tests}

Twenty-six putative E. ictaluri isolates (whitish, pinpoint colonies) were cultured on BHIA at $28{ }^{\circ} \mathrm{C}$ for $48 \mathrm{~h}$ and then subjected to biochemical characterization. Gram staining was conducted and the bacterial morphology was examined under a light microscope (Zeiss, Jena, Germany). Oxidase and catalase tests were conducted on all 26 isolates, as described by Crumlish et al. (2002). Other biochemical tests were performed using the API 20E kit (bioMérieux, Marcy l'Etoile, France), following the manufacturer's instructions.

2.3. DNA extraction and polymerase chain reaction (PCR) confirmation of E. ictaluri

Genomic DNA of all bacterial isolates $(\mathrm{n}=26)$ was extracted using the InstaGene Matrix kit (Bio-Rad, California, USA). PCR tests were performed using genus- and species-specific primers targeting the fimbrial gene of E. ictaluri (generating 848 and 470 bp amplicons, respectively), as previously described (Sakai et al., 2009) (Table 2). Genomic DNA of E. ictaluri LMG7860 from striped catfish (purchased from BCCM/LMG Bacteria Collection, Gent, Belgium) was used as a positive control and nuclease-free water was used as a negative control. PCR reaction mixtures $(20 \mu \mathrm{L})$ included $10 \mu \mathrm{L}$ Gotaq Green Master Mix (Promega, Wisconsin, USA), $1.5 \mu \mathrm{L}(10 \mu \mathrm{M})$ of the specific primer (forward and reverse), $3 \mu \mathrm{L}$ DNA template, and 4 $\mu \mathrm{L}$ DNA-free distilled water. The mixtures were then placed in a thermal cycler for amplification under the following conditions: initial denaturation for 4 min at $94{ }^{\circ} \mathrm{C}$; 35 cycles consisting of denaturation at $95{ }^{\circ} \mathrm{C}$ for $30 \mathrm{~s}$, annealing at $58{ }^{\circ} \mathrm{C}$ for $30 \mathrm{~s}$, extension at $72{ }^{\circ} \mathrm{C}$ for $60 \mathrm{~s}$; and a final extension for 7 min at $72{ }^{\circ} \mathrm{C}$. The amplified products were then analyzed by electrophoresis on a $1 \%$ agarose gel containing a RedSafe nucleic acid staining solution (Intron, Gyeonggi-do, Korea). The images were digitally captured using a gel image system (Bio-Rad, California, USA). 


\subsection{S rRNA and gyrB amplification, sequencing, and phylogenetic analysis}

Nine representative isolates (Ed.HB-02, Ed.TQ-06, Ed.HD-09, Ed.TB-07, Ed.YB-08, Ed.BN-04, Ed.HY-06, Ed.SL-07, and Ed.HNa-02) originating from nine different provinces were selected for further genetic analysis. The $16 S$ rRNA and gyrB genes were amplified using the universal bacterial primer $(27 \mathrm{~F} / 1525 \mathrm{R}, ~ \sim 1500 \mathrm{bp})$ (Weisburg et al., 1991) and gyrB primer (1245F/1949R, 1860 bp) (Griffin et al., 2014); and the purified PCR products were sequenced (Macrogen, Seoul, Korea). Bacterial species identification was performed using a Basic Local Alignment Search Tool (BLAST) nucleotide search on the GenBank database. The nucleotide sequences of $16 S r R N A$ and gyrBgenes of representative E. ictaluri isolates in this study and closely related sequences retrieved from GenBank were aligned using ClustalW (Thompson et al., 1994). Phylogenetic trees were then constructed using the neighbor-joining method with a bootstrap of 1000 replicates (Saitou \& Nei, 1987) performed by MEGA 10 software (Kumar et al., 2018).

\subsection{Detection of putative virulence genes}

Amplification of the six virulence genes of E. ictaluri,including the type III secretion system (T3SS), ersC , putative T3SS effector eseI and its chaperone, escD, type IV secretion system (T4SS), virD4, type VI secretion system (T6SS), evpC , and ureA-C genes of the urease operon, were performed on all 26 isolates using specific primers and protocols outlined by Rogge et al. (2013) (Table 2). Nuclease-free water was used as a no-template control. Thermal conditions were used for each of the respective primer sets as described previously (Rogge et al., 2013) with 1 cycle of $98{ }^{\circ} \mathrm{C}$ for $30 \mathrm{~s}, 35$ cycles of $98{ }^{\circ} \mathrm{C}$ for $10 \mathrm{~s}, 56{ }^{\circ} \mathrm{C}$ for $30 \mathrm{~s}$, and $72{ }^{\circ} \mathrm{C}$ for $2 \mathrm{~min}$, followed by a final extension at $72{ }^{\circ} \mathrm{C}$ for $5 \mathrm{~min}$. The PCR products were stained and visualized as described above.

\subsection{Antimicrobial susceptibility test}

The susceptibility of E. ictaluri isolates to antibiotics was examined using the disk diffusion method according to the guidelines of the Clinical Laboratory Standards Institute (CLSI, 2018). Sixteen antibiotics (Oxoid, Hampshire, United Kingdom) comprising 11 antibiotic classes/subclasses were tested, including two penicillins: oxacillin $(\mathrm{Ox}, 1 \mu \mathrm{g})$ and amoxicillin $(\mathrm{Ax}, 10 \mu \mathrm{g})$; one $\beta$-lactam/ $\beta$-lactamase inhibitor combination ( BL/BLIs): amoxicillin-clavulanic acid (Ac, 20/10 $\mu \mathrm{g}$ ); three cephalosporins: cefotaxime (Ct, $30 \mu \mathrm{g})$, cefuroxime $(\mathrm{Cu}, 30 \mu \mathrm{g})$, and ceftriaxone $(\mathrm{Cx}, 30 \mu \mathrm{g})$; one macrolide: erythromycin (Er, $15 \mu \mathrm{g})$; one quinolone: nalidixic acid ( $\mathrm{Na}, 30 \mu \mathrm{g}$ ); one sulfonamide: sulfamethoxazole/trimethoprim (ST, 23.75/1.25 $\mu \mathrm{g}$ ); one aminoglycosides: neomycin (Ne, $30 \mu \mathrm{g})$; one glycopeptide: vancomycin (Va, $30 \mu \mathrm{g})$; two fluoroquinolones: ofloxacin (Of, $5 \mu \mathrm{g}$ ) and norfloxacin (No, $10 \mu \mathrm{g}$ ); two tetracyclines: doxycycline (Dx, $30 \mu \mathrm{g}$ ) and oxytetracycline (OTC, $30 \mu \mathrm{g})$; and one amphenicol: florfenicol ( $\mathrm{Fl}, 30 \mu \mathrm{g})$.

E. ictaluri isolates were grown in Mueller Hinton ( $\mathrm{MH})$ broth and adjusted to a McFarland turbidity of 0.5. The suspension was then spread onto $\mathrm{MH}$ agar using a sterilized cotton swab. Antibiotic discs were placed on the inoculated plates and incubated at $28^{\circ} \mathrm{C}$ for $48 \mathrm{~h}$. The inhibition zone diameters were recorded and classified as susceptible, intermediate, or resistant according to the standard CLSI (2020) method valid for Enterobacterales. In the case of amoxicillin and neomycin, for which CLSI (2020) assessment does not exist, the clinical breakpoints according to the European Committee on Antimicrobial Susceptibility Testing standard (EUCAST, 2021) were applied. The multiple antibiotic resistance (MAR) index of the isolates was calculated as described by Krumperman (1983), in which MAR =a/b, where ' $a$ ' represents the number of antibiotics to which the isolate is resistant, and ' $b$ ' represents the total number of antibiotics to which the isolates are exposed for susceptibility testing.

\subsection{Challenge experiment}

Apparently healthy Nile tilapia juveniles, O. niloticus $(\sim 28 \mathrm{~g})$, were obtained from a commercial tilapia hatchery in northern Vietnam for challenge experiments. The fish were acclimatized to the experimental conditions for one week before conducting experiments. Ten fish were randomly checked for E. ictaluri free status by Gram staining, inspection of the spleen and head kidney for the presence of bacteria, and by streaking these tissue samples on BHIA plates before beginning the experiments. Four representative 
bacterial isolates (Ed.HB-02, Ed.HD-09, Ed.YB-08, and Ed.TB-07) were selected for experimental infection. Each isolate was grown in BHIB medium at $28{ }^{\circ} \mathrm{C}$ for $36 \mathrm{~h}$. The viable bacterial density of the stock suspensions was determined using the plate count method. The bacterial density of the stock suspension was then adjusted to approximately $1 \times 10^{8}$ colony forming units (CFUs)/mL by adding an equivalent volume of phosphate-buffered saline. Ten-fold serial dilutions of bacteria from $10^{2}-10^{8} \mathrm{CFU} / \mathrm{mL}$ were prepared for the virulence test. With each bacterial isolate, fish were divided into eight $100 \mathrm{~L}$ groups (15 fish/tank, two replicates). Fish from seven groups were intraperitoneally injected with $0.1 \mathrm{~mL}$ of the serial bacterial suspensions to reach the respective bacterial concentrations of $10^{1}-10^{7} \mathrm{CFU} / \mathrm{fish}$. In the control group, fish were injected with normal saline solution without bacteria. Mortality was observed daily for 2 weeks. Representative moribund and freshly dead fish $(\mathrm{n}=3)$ from each challenge group and apparently healthy fish from the control groups (at the end of the experiment, $n=3$ ) were subjected to bacterial re-isolation and histopathological analysis.

\subsection{Histopathological examination}

Representative moribund tilapia $(\mathrm{n}=3)$ from each challenge group and apparently healthy tilapia $(\mathrm{n}=3)$ from the control groups were examined for histopathological changes. Tissues of affected fish (spleen, kidney, liver, and brain) were collected and preserved in $10 \%$ buffered formalin. After fixation for $24 \mathrm{~h}$, sampled tissues were dehydrated in an ethanol series, embedded in paraffin, and sectioned at $5 \mu \mathrm{m}$ thickness. The sections were then stained with hematoxylin and eosin, following the standard histological protocol. Histopathological changes were examined under a light microscope equipped with a digital camera (Olympus, Tokyo, Japan).

\section{RESULTS}

3.1. Disease history and epidemiological factors

Between February 2019 and March 2021, 26 tilapia disease outbreaks, located in 9 provinces in northern Vietnam, were investigated. In tilapia-farming systems using earth-pond and floating cages in rivers in the delta region (Hai Duong, Thai Binh, Hung Yen, Bac Ninh, and Ha Nam provinces), disease outbreaks often occurred from July to October, while for the cage culture in reservoirs in mountainous provinces, such as Hoa Binh, Yen Bai, Tuyen Quang, and Son La, outbreaks occurred from December to March. Water temperature during disease outbreaks ranged from $23.3-29.1{ }^{\circ} \mathrm{C}$. The 26 affected farms included 5 earth ponds and 21 floating cage farms, with red tilapia ( 8 farms) and Nile tilapia (18 farms). Tilapia seeds included both imported (19 farms) and domestic ( 7 farms). The mortality estimated by farmers during disease outbreaks ranged from $30 \%-65 \%$ (Table 1). In all disease outbreaks, clinically sick fish showed gross signs of pale gills due to anemia; no clear external symptoms were observed except for a darkened body in Nile tilapia and pale color in hybrid red tilapia (at a low frequency). Internally, numerous white spots appeared on the spleen and head kidney and were occasionally observed in the liver. Hemorrhage or congestion in the liver was also recorded at a high frequency.

\subsection{Bacterial isolation and identification}

In total, 341 infected fish collected from 26 tilapia farms (10-15 fish/farm) were subjected to bacterial isolation. A typical whitish pinpoint colony was predominantly recovered from the spleen, kidney, and liver of most diseased fish from each farm (Table 1). Twenty-six representative isolates (one per farm) were selected for further analysis. All isolates were gram-negative, rod-shaped, oxidase-negative, and catalasepositive. Other biochemical features were homogeneous among the 26 isolates and identical to the reference isolates of E. ictaluri from red tilapia (Dong et al., 2019) and striped catfish (Crumlish et al., 2002), except for Voges-Proskauer, which varied among isolates (Table 3). The specific PCR results showed that all 26 isolates were positive for both the Edwardsiella genus and E. ictaluri species, as evidenced by the presence of $848 \mathrm{bp}$ and $470 \mathrm{bp}$ amplicons, respectively (Figure S1).

Partial $16 S$ rRNA and gyrB sequences (1500 bp and $1860 \mathrm{bp}$, respectively) were successfully amplified and sequenced from all nine representative isolates. Nucleotide sequences of these isolates were deposited in the GenBank database under the accession numbers MZ382896-MZ382904 for 16S rRNA and MZ576507- 
MZ576515 for $\operatorname{gyr} B$. Nucleotide BLAST results revealed that all isolates showed $99.93 \%-100 \%$ and $99.41 \%^{-}$ $100 \%$ nucleotide identity with the respective $16 S r R N A$ and gyrB sequences of the reference strains, E. ictaluri ATCC 33202 (NR024769), E. ictaluri2234 (MH540086.1), and less than 95\% identity to other species in theEdwardsiella genus. Phylogenetic analysis of both $16 S$ rRNAand gyrB gene sequences also demonstrated that nine isolates in this study were grouped in the same cluster as other E. ictaluriisolates and were separated from other species in the same genus (Figure 2).

Taken together, the results of biochemical tests, genus- and species-specific PCR, and sequencing of $16 S$ $r R N A$ and gyrBconfirmed that 26 bacterial isolates recovered from disease outbreaks in this study were $E$. ictaluri .

3.3. Detection of E. ictaluri virulence genes

PCR amplification results for six virulence genes revealed that all 26 isolates were $\operatorname{esr} C{ }^{+}$, evp $C{ }^{+}$, and ure $A-C+$ (Figure 3, Table 4). However, all isolates were PCR-negative for the three remaining genes (eseI ${ }^{-}, e s c D^{-}$, and $\operatorname{virD4^{-}}$ ) (Table 4).

\subsection{Antimicrobial susceptibility}

Overall, the E. ictaluri isolates were susceptible to antimicrobials belonging to the following classes/subclasses: $\beta$-lactam/ $\beta$-lactamase inhibitor combination, cephems, tetracyclines, and fluoroquinolones, while they were resistant to antimicrobials belonging to the penicillin, macrolide, sulfonamide, amphenicol, and glycopeptide subclasses (Tables 4 and 5). More than $80 \%$ of the isolates were susceptible to cefotaxime, ceftriaxone, cefuroxime, doxycycline, oxytetracycline, ofloxacin, and norfloxacin; $73.1 \%$ of the isolates were also susceptible to the combination of amoxicillin and clavulanate (Tables 4 and 5). However, $80.8 \%-100 \%$ of isolates were resistant to amoxicillin, oxacillin, erythromycin, sulfamethoxazole/trimethoprim, florfenicol, and vancomycin. The resistance frequencies of E. ictaluri isolates to nalidixic acid and neomycin were $27.0 \%$ and $19.2 \%$, respectively (Table 5 ). The MAR values of $E$. ictaluriisolates ranged from $0.25-0.5$, corresponding to 4-8 antibiotics or 12 resistant phenotypes (Table S1). The highest frequency of the isolates $(34.6 \%)$ was observed to resist seven tested antimicrobial agents, followed by five and six agents (23\% both). The frequencies of the isolates resistant to 2 and 8 drugs were 11.5 and $7.7 \%$, respectively (Table S1).

\subsection{Virulence test and histopathology}

The experimental challenge using four multi-drug resistant E. ictaluri isolates, Ed.HB-02, Ed.HD-09, Ed.YB08, and Ed.TB-07 (Table 1), resulted in $\mathrm{LD}_{50}$ values of 42, 54, 46, and $61 \mathrm{CFU} /$ fish, respectively (Figure 4). Overall, the mortality rates were dose-dependent. The fish that received high doses $\left(10^{6}-10^{7} \mathrm{CFU} / \mathrm{fish}\right)$ showed $77 \%-97 \%$ mortality within 3 days and reached almost $100 \%$ at $5-6$ days post infection (dpi). The fish that died on day 3 or earlier showed visceral decay, fluid accumulation in the fish abdomen, and unclear visceral white spots. After $3 \mathrm{dpi}$, all dead fish exhibited clear white spots in the viscera, similar to those of the naturally infected fish collected from ponds/cages (Figure 5). In the groups injected with lower doses $\left(10^{1}-10^{2} \mathrm{CFU} /\right.$ fish), white spots clearly appeared in the spleen, head kidney, and posterior kidney after 4-5 dpi and in the liver after $10 \mathrm{dpi}$. Noticeably, apart from some affected fish with darker color, most infected fish in the challenge test showed no obvious external clinical signs. Bacterial isolation from the internal organs of the infected fish resulted in dominant pinpoint colonies, which were identical to the colony morphology of E. ictaluri and tested positive by species-specific assay (data not shown). No bacteria were recovered from the clinically healthy fish in the control groups.

The histopathological manifestation of E. ictaluri -infected fish reached consensus at a similar challenge dose among the four bacterial isolates used. The lesions accurately reflected the gross features of the affected organs. Severe multifocal necrosis and pyogranulomas were observed in the spleen and kidneys (Figure 6 A, C). At high magnification, splenic focal necrosis surrounded by collagenous fibers, infiltration of inflammatory cells, the presence of basophilic rod-shaped bacterial clumps, and pyknosis and karyorrhexis was clearly observed (Figure 6B). Similarly, the kidneys of infected fish exhibited pyogranulomas, multifocal necrosis, and hyaline droplet accumulation in the kidney tubular epithelium (Figure 6D). The affected livers showed 
severe congestion, hepatic lipidosis, and tissue degeneration with an occasional presence of multifocal necrotic areas (Figure 6E-F). The brains of diseased fish also exhibited severe congestion and inflammation in the primitive meninges and periventricular gray zone of the optic tectum (Figure $6 \mathrm{G}-\mathrm{H}$ ).

\section{DISCUSSION}

Edwardsiellosis caused by E. ictaluri in Nile tilapia (O. niloticus ) was reported for the first time in the western hemisphere (Soto et al. , 2012) and later in farmed hybrid red tilapia (Oreochromis sp.) in Vietnam in 2016 (Dong et al., 2019). Comparative genomic analysis of E. ictalurifrom different fish hosts revealed that E. ictaluri isolates from tilapia are a novel genotype, which differs from the currently circulating catfish genotypes (Machimbirike et al., 2021; Reichley et al., 2017). This comprehensive follow-up investigation and findings suggest that this emerging pathogen is well established and has spread in tilapia farms in northern Vietnam. Although the introduction (source of infection) remains inconclusive, the notation of most affected farms that used imported stocks for aquaculture with improper diagnostic screening suggests a possible foreign introduction of this pathogen. Alternatively, there were a proportion of disease outbreak farms that used domestic stock sources. This implies that this pathogen may have been circulated domestically from a previously unknown introduction to Vietnam (Dong et al., 2019) and continued to spread thereafter through contaminated seeds and/or contaminated water bodies during disease outbreaks. The detection of E. ictaluri associated with disease outbreaks from two different continents (America and Asia) highlights the risk of transboundary spread and potential impact on the tilapia industry. Countries that rely on imported tilapia stocks for aquaculture, such as Vietnam, may have the same theoretical risk for the introduction of this emerging pathogen. Therefore, active surveillance, early diagnostic screening, and biosecurity measures are highly recommended for these countries.

The present study also identified some potential risk factors associated with disease outbreaks caused by E. ictaluri in tilapia, including the influence of temperature, fish size, and belated detection due to ambiguous clinical symptoms. The disease occurs in cool seasons, including autumn (ponds and cage culture in the rivers) and spring (cage culture in deep lakes/hydropower reservoirs) when the temperature range is approximately $23-29{ }^{\circ} \mathrm{C}$ due to the capacity of E. ictaluri to be motile at this temperature range (Hawke et al., 1998); thus, this temperature range is suitable for this pathogen to attach, propagate, and cause disease outbreaks. The incidence of $E$. ictaluriinfections associated with cool seasons in other host species, including catfish and non-catfish species, has been previously reported (Hawke et al., 1998; Pham et al., 2021; Takeuchi et al., 2016). In addition, the current survey results revealed that tilapia of a small size $(<350 \mathrm{~g})$ were more susceptible to E. ictaluriinfection, which tended to cause acute death with higher mortality than at adult stages. Farming observations revealed that in cage lines raising tilapia culture on the same rivers/lakes, cages raising fish less than $350 \mathrm{~g}$ were found to be susceptible and have higher mortality rates than those of other cages raising marketable size fish. The fish stage influences the susceptibility to infection similar to that of $E$. ictaluri infection in catfish, in which the disease occurs in all ages of catfish, but fingerlings and juveniles have been demonstrated to be more susceptible than adult fish (Dung et al., 2008; Hawke et al., 1998). Further epidemiological and experimental studies are needed to determine the optimal temperature and influence of age on the circulation and outbreaks caused by this pathogen in tilapia. Moreover, E. ictaluri- affected fish did not exhibit recognizable external symptoms, causing misleading presumptive disease diagnosis and untimely treatment efforts.

Virulence factors of pathogenic bacteria may be encoded by specific regions of the prokaryotic genome, termed pathogenicity islands (Hacker et al., 1990). Pathogenicity islands are present in the genomes of pathogenic strains, but are absent in the genomes of nonpathogenic members of the same or related species (Hacker \& Kaper, 2000). The detection of identical virulence gene profiles among 26 isolates from nine provinces implied the circulation of a homologous strain. The presence of $\operatorname{esr} C$, evpC , and ure $A-C$ genes, which are well-known for enabling the bacteria to survive and replicate intracellularly (Booth et al., 2006; Chen et al., 2017; Hu et al., 2014; Moore et al., 2002; Rogge \& Thune, 2011), in all the isolates identified in this

study suggests their potential virulence and management difficulty using antimicrobials. The presence of these genes has also been reported in tilapia isolates from the western hemisphere by Griffin et al. (2016). 
However, while the virD, eseI, and its chaperone escD genes are present in US channel catfish (Ictalurus punctatus ) isolates (Rogge et al., 2013), they are absent in all tilapia isolates from this study and from the western hemisphere (Griffin et al., 2016). These findings support previous studies showing that the variability in virulence genes of E. ictaluri is related to host fish species (Griffin et al., 2016). Although E. ictaluri isolates from Asia or the western hemisphere harbor a similar pattern of six examined virulence genes, other potential virulence factors may exist in E. ictaluri isolates in Vietnam, which have contributed to and create their hypervirulence compared to those of the western hemisphere. Thus, whole genome sequencing and comparative analysis between isolates from two continents are needed to understand this evolution.

Although disease caused by E. ictaluri was first detected only a few years ago and affected farmed tilapia in Vietnam, the high levels of antibiotic resistance pose potential risks; thus, emergent action is needed to mitigate the disease and spread of this pathogen. The high resistance frequencies of this bacterium to various antimicrobials belonging to several classes and subclasses may be the consequence of inappropriate usage of these drugs for disease control in tilapia farms, leading to 12 multi-drug resistance phenotypes (Dang et al., 2021). Of note, these MAR isolates may have also been introduced to Vietnam elsewhere and continue to spread and acquire more resistance. Some resistance was likely intrinsic. Specifically, approximately $85 \%$ of the E. ictaluri isolates from tilapia were resistant to erythromycin, which is consistent with a previous report on the intrinsic resistance of Edwardsiella species to macrolides (Stock \& Wiedemann, 2001). The intrinsic resistance of gram-negative bacteria and specifically of Edwardsiella species to glycopeptides has also been widely shown (Breijyeh et al., 2020; Stock \& Wiedemann, 2001) and is reaffirmed by the extremely high frequency of vancomycin resistance in E. ictaluri . However, some resistance likely resulted from the misuse of antimicrobials. For example, florfenicol is highly effective in E. ictaluri infection control in catfish (Gaunt et al., 2015), but allE. ictaluri isolates from tilapia in this study are resistant to this drug. Similarly, high resistance frequencies with two other approved antibiotics used in aquaculture in Vietnam, namely amoxicillin (80.8\%) and sulfamethoxazole/trimethoprim (100\%), were also recorded. Nevertheless, alternatives to antibiotics, such as vaccines, probiotics, and bioactive metabolites, should be further explored to tackle this emerging, pathogenic, multi-drug resistant bacterium.

The multidrug-resistant E. ictaluri isolates in this study were extremely highly virulent. In comparison to previous studies where the $\mathrm{LD}_{50}$ was $3.2 \times 10^{4} \mathrm{CFU} / \mathrm{mL}$ in yellow catfish (Kim \& Park, 2015) and $5.1 \times 10^{4}$ $\mathrm{CFU} / \mathrm{mL}$ in Nile tilapia (Soto et al., 2013), E. ictaluri isolates in this study required only $42-61 \mathrm{CFU} /$ fish to kill $50 \%$ of the tilapia population. At higher doses, the results are similar to those reported by Dong et al. (2019) when fish challenged with $10^{5}-10^{7} \mathrm{CFU} /$ fish result in $95 \%-100 \%$ mortality within 9 days post infection. Gross signs and histopathological manifestations are similar to those of previous studies that show severe tissue destruction, especially in the spleen and head kidney, two major lymphoid organs that play important roles in defense against infection (Soto et al., 2012; Dong et al., 2019). The failure of these organs may explain the high mortality in experimentally challenged fish (Dong et al., 2019; Soto et al., 2013). Since the current investigation suggested homologous strains of the collected $E$. ictaluri isolates, an autogenous vaccine might be the best option to combat this emerging disease in the present time before a better vaccine candidate for a wider region is discovered.

In conclusion, this follow-up investigation from a previous case report highlights the establishment and widespread use of extremely virulent, multidrug-resistant E. ictaluri isolates as an emerging threat to the tilapia farming industry in Vietnam. The arrival of this pathogen likely involved both imported and domestic stocks. Therefore, increased awareness, early diagnostic testing, and biosecurity measures at both national and international levels are needed to prevent its transboundary spread and negative impact on the tilapia industry.

\section{ACKNOWLEDGEMENTS}

The authors are grateful to Dr. Saengchan Senapin (National Center for Genetic Engineering and Biotechnology, BIOTEC, Pathum Thani, Thailand) and Dr. Le Viet Dung for their valuable comments on the manuscript. This research was funded by the Vietnam National Foundation for Science and Technology Development (NAFOSTED) under grant number 106.05-2020.18 


\section{CONFLICT OF INTEREST}

The authors declare no conflict of interest. The funders played no role in the design of the study; collection, analysis, or interpretation of data; in the writing of the manuscript; or in the decision to publish the results.

\section{ETHICS STATEMENT}

The authors confirm that the ethical policies of the journal, as noted on the journal's author guidelines page, have been adhered to. Ethical approval for the challenge experiments was obtained from the Faculty of Fisheries, Vietnam National University of Agriculture Animal Care and Use committee FFVNUA-ACUC, approval number: 15620-1-KHCN-FFVNUA.

\section{REFERENCES}

Baldwin, T. J., \& Newton, J. C. (1993). Pathogenesis of enteric septicemia of channel catfish, caused by Edwardsiella ictaluri : bacteriologic and light and electron microscopic findings. Journal of Aquatic Animal Health, 5 (3), 189-198. doi:10.1577/15488667(1993)005<0189:POESOC >2.3.CO;2

Booth, N. J., Elkamel, A., \& Thune, R. L. (2006). Intracellular replication of Edwardsiella ictaluriin channel catfish macrophages. Journal of Aquatic Animal Health, 18(2), 101-108. doi:10.1577/H05-025.1

Breijyeh, Z., Jubeh, B., \& Karaman, R. (2020). Resistance of Gram-negative bacteria to current antibacterial agents and approaches to resolve it. Molecules, 25 (6), 1340. doi:10.3390/molecules25061340

Chen, H., Yang, D., Han, F., Tan, J., Zhang, L., Xiao, J., Zhang, Y., \& Liu, Q. (2017). The bacterial T6SS effector EvpP prevents NLRP3 inflammasome activation by inhibiting the Ca2+-dependent MAPK-Jnk pathway. Cell Host $\& 3$ Microbe, 21 (1), 47-58. doi:10.1016/j.chom.2016.12.004

CLSI (2018). Performance Standards for Antimicrobial Disk and Dilution Susceptibility Tests for Bacteria Isolated from Animals . $3^{\text {rd }}$ Edition. CLSI document M31-A3. Wayne, PA: Clinical Laboratory Standards Institute

CLSI. (2020). Performance Standards for Antimicrobial Susceptibility Testing . 30 ${ }^{\text {th }}$ Edition. CLSI supplement M100. Wayne, PA: Clinical Laboratory Standards Institute.

Crumlish, M., Dung, T., Turnbull, J., Ngoc, N., \& Ferguson, H. (2002). Identification of Edwardsiella ictaluri from diseased freshwater catfish, Pangasius hypophthalmus (Sauvage), cultured in the Mekong Delta, Vietnam. Journal of Fish Diseases, 25 (12), 733-736.

Dang, L. T., Nguyen, L. H. T., Pham, V. T., \& Bui, H. T. (2021). Usage and knowledge of antibiotics of fish farmers in small-scale freshwater aquaculture in the Red River Delta, Vietnam. Aquaculture Research , 52(8), 3580-3590. doi:10.1111/are.15201

Dong, H., Senapin, S., Jeamkunakorn, C., Nguyen, V., Nguyen, N., Rodkhum, C., Khunrae, P., \& Rattanarojpong, T. (2019). Natural occurrence of edwardsiellosis caused by Edwardsiella ictaluri in farmed hybrid red tilapia(Oreochromi s sp.) in Southeast Asia. Aquaculture, 499 , 17-23. doi:10.1016/j.aquaculture.2018.09.007

Dong, H. T., Nguyen, V. V., Phiwsaiya, K., Gangnonngiw, W., Withyachumnarnkul, B., Rodkhum, C., \& Senapin, S. (2015). Concurrent infections of Flavobacterium columnare andEdwardsiella ictaluri in striped catfish, Pangasianodon hypophthalmus in Thailand. Aquaculture, 448, 142-150. doi:10.1016/j.aquaculture.2015.05.046

Dung, T., Crumlish, M., Ngoc, N., Thinh, N., \& Thy, D. (2004). Investigate the disease caused by the genus Edwardsiella from Tra catfish (Pangasianodon hypophthalmus ). Journal of Science, Can Tho University, 1 , 23-31.

Dung, T. T., Haesebrouck, F., Tuan, N. A., Sorgeloos, P., Baele, M., \& Decostere, A. (2008). Antimicrobial susceptibility pattern of Edwardsiella ictaluri isolates from natural outbreaks of bacillary 
necrosis of Pangasianodon hypophthalmus in Vietnam. Microbial Drug Resistance, 14 (4), 311-316. doi:10.1089/mdr.2008.0848

EUCAST. (2021). The European Committee on Antimicrobial Susceptibility Testing . Breakpoint tables for interpretation of MICs and zone diameters. Version 11.0, 2021. Retrieved from https://eucast.org/

FAO. (2017). Outbreaks of Tilapia lake virus (TiLV) threaten the livelihoods and food security of millions of people dependent on tilapia farming. Rome: Italy. Retrieved from http://www.fao.org/documents/ card/en/c/3ce1da5b-1529-4e7c-8b88-7adfef8d138c/

FAO. (2018). The state of world fisheries and aquaculture 2018. Meeting the Sustainable Development Goals. Rome. Licence: CC BY-NC-SA 3.0 IGO.

Ferguson, H., Turnbull, J., Shinn, A., Thompson, K., Dung, T. T., \& Crumlish, M. (2001). Bacillary necrosis in farmed Pangasius hypophthalmus (Sauvage) from the Mekong Delta, Vietnam. Journal of Fish Diseases, 24 (9), 509-513. doi:10.1046/j.13652761.2001.00308.x

Gaunt, P. S., Chatakondi, N., Gao, D., \& Endris, R. (2015). Efficacy of florfenicol for control of mortality associated with Edwardsiella ictaluri in three species of catfish. Journal of Aquatic Animal Health, 27 (1), 45-49. doi:10.1080/08997659.2014.976672

Griffin, M., Reichley, S., Greenway, T., Quiniou, S., Ware, C., Gao, D., Gaunt, P., Yanong, R., Pouder, D., \& Hawke, J. (2016). Comparison of Edwardsiella ictaluri isolates from different hosts and geographic origins. Journal of Fish Diseases, 39 (8), 947-969. doi:10.1111/jfd.12431

Griffin, M. J., Ware, C., Quiniou, S. M., Steadman, J. M., Gaunt, P. S., Khoo, L. H., \& Soto, E. (2014).Edwardsiella piscicida identified in the southeastern USA by gyrB sequence, species-specific and repetitive sequence-mediated PCR.Diseases of Aquatic Organisms, 108 (1), 23-35. doi:10.3354/dao02687

Hacker, J., Bender, L., Ott, M., Wingender, J., Lund, B., Marre, R., \& Goebel, W. (1990). Deletions of chromosomal regions coding for fimbriae and hemolysins occur in vitro and in vivo in various extra intestinal Escherichia coliisolates. Microbial Pathogenesis, 8 (3), 213-225. doi:10.1016/0882-4010(90)90048-U

Hacker, J., \& Kaper, J. B. (2000). Pathogenicity islands and the evolution of microbes. Annual Reviews in Microbiology, 54 (1), 641-679. doi:10.1146/annurev.micro.54.1.641

Hassan, E. S., Mahmoud, M. M., Kawato, Y., Nagai, T., Kawaguchi, O., Iida, Y., Yuasa, K., \& Nakai, T. (2012). Subclinical Edwardsiella ictaluri infection of wild ayuPlecoglossus altivelis . Fish Pathology, 47 (2), 64-73. doi:10.3147/jsfp.47.64

Hawke, J. P., Durborow, R., Thune, R., \& Camus, A. (1998). Enteric septicemia of catfish. SRAC Publication (477).

Hawke, J. P., Kent, M., Rogge, M., Baumgartner, W., Wiles, J., Shelley, J., Savolainen, L. C., Wagner, R., Murray, K., \& Peterson, T. S. (2013). Edwardsiellosis caused byEdwardsiella ictaluri in laboratory populations of zebrafishDanio rerio. Journal of Aquatic Animal Health, 25 (3), 171-183. doi:10.1080/08997659.2013.782226

Hawke, J. P., McWhorter, A. C., Steigerwalt, A. G., \& Brenner, D. J. (1981). Edwardsiella ictaluri sp. nov., the causative agent of enteric septicemia of catfish. International Journal of Systematic and Evolutionary Microbiology, 31 (4), 396-400. doi:10.1099/00207713-31-4-396

Hu, W., Anand, G., Sivaraman, J., Leung, K. Y., \& Mok, Y.-K. (2014). A disordered region in the EvpP protein from the type VI secretion system of Edwardsiella tardais essential for EvpC binding. PloS One, 9 (11), e110810. doi:10.1371/journal.pone.0110810

Iwanowicz, L. R., Griffin, A. R., Cartwright, D. D., \& Blazer, V. S. (2006). Mortality and pathology in brown bullheads Amieurus nebulosus associated with a spontaneousEdwardsiella ictaluri outbreak under tank culture conditions.Diseases of Aquatic Organisms, 70 (3), 219-225. doi:10.3354/dao070219 
Kasornchandra, J., Rogers, W., \& Plumb, J. (1987). Edwardsiella ictaluri from walking catfish,Clarias batrachus L., in Thailand. Journal of Fish Diseases, 10 (2), 137-138. doi:10.1111/j.1365-2761.1987.tb00729.x

Kim, J. D., \& Park, S. W. (2015).Edwardsiella ictaluri infection in cultured yellow catfishPelteobagrus fulvidraco fingerlings in Korea. Korean Journal of Fisheries and Aquatic Sciences, 48 (5), 725-730. doi:10.5657/KFAS.2015.0725

Kumar, S., Stecher, G., Li, M., Knyaz, C., \& Tamura, K. (2018). MEGA X: molecular evolutionary genetics analysis across computing platforms. Molecular Biology and Evolution, 35 (6), 1547-1549. doi:10.1093/molbev/msw054

Li, L., Wang, R., Liang, W., Huang, T., Huang, Y., Luo, F., Lei, A., Chen, M., \& Gan, X. (2015). Development of live attenuated Streptococcus agalactiae vaccine for tilapia via continuous passage in vitro. Fish E3 Shellfish Immunology, 45 (2), 955-963. doi:10.1016/j.fsi.2015.06.014

Liu, J. Y., Li, A. H., Zhou, D. R., Wen, Z. R., \& Ye, X. P. (2010). Isolation and characterization of Edwardsiella ictaluri strains as pathogens from diseased yellow catfish Pelteobagrus fulvidraco (Richardson) cultured in China.Aquaculture Research, 41 (12), 1835-1844. doi:10.1111/j.1365-2109.2010.02571.x

Machimbirike, V. I., Uthaipaisanwong, P., Khunrae, P., Dong, H. T., Senapin, S., Rattanarojpong, T., \& Sutheeworapong, S. (2021). Comparative genomics of Edwardsiella ictaluri revealed four distinct host-specific genotypes and thirteen potential vaccine candidates. Genomics, 113 (4), 1976-1987. doi:10.1016/j.ygeno.2021.04.016

MARD. (2019). Decision to approve the plan of tilapia farming development by 2020, driven by 2030 . Issued on May, 6th 2016 by the Ministry of Agriculture and Rural Development, Vietnam (MARD).

Moore, M. M., Fernandez, D. L., \& Thune, R. L. (2002). Cloning and characterization of Edwardsiella ictaluri proteins expressed and recognized by the channel catfishIctalurus punctatus immune response during infection.Diseases of Aquatic Organisms, 52 (2), 93-107. doi:10.3354/dao052093

Ngoc Phuoc, N., Richards, R., \& Crumlish, M. (2020). Establishing bacterial infectivity models in striped Catfish Pangasianodon hypophthalmus (Sauvage) withEdwardsiella ictaluri . Journal of Fish Diseases, 43 (3), 371-378. doi:10.1111/jfd.13135

Pham, K. D., Nguyen, S. V., Odegard, J., Gjoen, H. M., \& Klemetsdal, G. (2021). Case study development of a challenge test against Edwardsiella ictaluri in Mekong striped catfish (Pangasianodon hypophthalmus), for use in breeding: Estimates of the genetic correlation between susceptibilities in replicated tanks. Journal of Fish Diseases, 44 (5), 553-561. doi:10.1111/jfd.13292

Plumb, J., \& Sanchez, D. (1983). Susceptibility of five species of fish to Edwardsiella ictaluri .Journal of Fish Diseases, 6 (3), 261-266. doi:10.1111/j.1365-2761.1983.tb00075.x

Prabu, E., Rajagopalsamy, C., Ahilan, B., Jeevagan, I. J. M. A., \& Renuhadevi, M. (2019). Tilapia - an excellent candidate species for world aquaculture: a review.Annual Research 83 Review in Biology , 1-14. doi:10.9734/arrb/2019/v31i330052

Reichley, S. R., Waldbieser, G. C., Soto, E., Lawrence, M. L., \& Griffin, M. J. (2017). Complete genome sequence of Edwardsiella ictaluri isolate RUSVM-1 recovered from Nile tilapia (Oreochromis niloticus ) in the Western Hemisphere.Genome Announcements, 5 (24), e00390-00317. doi:10.1128/genomeA.00390-17

Rogge, M. L., Dubytska, L., Jung, T. S., Wiles, J., Elkamel, A. A., Rennhoff, A., Oanh, D. T. H., \& Thune, R. L. (2013). Comparison of Vietnamese and US isolates ofEdwardsiella ictaluri. Diseases of Aquatic Organisms, 106 (1), 17-29. doi:10.3354/dao02620

Rogge, M. L., \& Thune, R. L. (2011). Regulation of the Edwardsiella ictaluri type III secretion system by $\mathrm{pH}$ and phosphate concentration through EsrA, EsrB, and EsrC.Applied and Environmental Microbiology, 77 (13), 4293-4302. doi:10.1128/AEM.00195-11 
Romero, J., Feijoo, C. G., \& Navarrete, P. (2012). Antibiotics in aquaculture-use, abuse and alternatives (Vol. 159). Croatia: InTech.

Saitou, N., \& Nei, M. (1987). The neighbor-joining method: a new method for reconstructing phylogenetic trees. Molecular Biology and Evolution, 4 (4), 406-425. doi:10.1093/oxfordjournals.molbev.a040454

Sakai, T., Kamaishi, T., Sano, M., Tensha, K., Arima, T., Iida, Y., Nagai, T., Nakai, T., \& Iida, T. (2008). Outbreaks of Edwardsiella ictaluri infection in ayuPlecoglossus altivelis in Japanese rivers. Fish Pathology, 43 (4), 152-157. doi:10.3147/jsfp.43.152

Sakai, T., Yuasa, K., Sano, M., \& Iida, T. (2009). Identification of Edwardsiella ictaluri andE. tarda by species-specific polymerase chain reaction targeted to the upstream region of the fimbrial gene. Journal of Aquatic Animal Health, 21 (2), 124-132. doi:10.1577/H08-061.1

Soto, E., Griffin, M., Arauz, M., Riofrio, A., Martinez, A., \& Cabrejos, M. E. (2012). Edwardsiella ictaluri as the causative agent of mortality in cultured Nile tilapia.Journal of Aquatic Animal Health, 24 (2), 81-90. doi:10.1080/08997659.2012.675931

Soto, E., Illanes, O., Revan, F., Griffin, M., \& Riofrio, A. (2013). Bacterial distribution and tissue targets following experimental Edwardsiella ictaluri infection in Nile tilapia Oreochromis niloticus . Diseases of Aquatic Organisms, 104 (2), 105-112. doi:10.3354/dao02593

Stock, I., \& Wiedemann, B. (2001). Natural antibiotic susceptibilities of Edwardsiella tarda, E. ictaluri, and E. hoshinae. Antimicrobial Agents and Chemotherapy, 45 (8), 2245-2255. doi:10.1128/AAC.45.8.22452255.2001

Suanyuk, N., Rogge, M., Thune, R., Watthanaphiromsakul, M., Champhat, N., \& Wiangkum, W. (2014). Mortality and pathology of hybrid catfish, Clarias macrocephalus (Gunther)xClarias gariepinus (Burchell), associated with Edwardsiella ictaluri infection in southern Thailand. Journal of Fish Diseases, 37 (4), 385-395. doi:10.1111/jfd.12127

Takeuchi, H., Hiratsuka, M., Oinuma, H., Umino, Y., Nakano, D., Iwadare, M., Tomono, R., Hori, K., Imai, T., \& Ishikawa, T. (2016). Infection status of ayu and other wild fish withFlavobacterium psychrophilum and Edwardsiella ictaluri in the Tama River, Japan. Fish Pathology, 51 (4), 184-193. doi:10.3147/jsfp.51.184

Waterstrat, P., Ainsworth, A., \& Capley, G. (1991). In vitro responses of channel catfish,Ictalurus punctatus, neutrophils to Edwardsiella ictaluri .Developmental \&3 Comparative Immunology, 15 (1-2), 53-63. doi:10.1016/0145-305X(91)90047-3

Weisburg, W. G., Barns, S. M., Pelletier, D. A., \& Lane, D. J. (1991). 16S ribosomal DNA amplification for phylogenetic study. Journal of Bacteriology, 173 (2), 697-703. doi:10.1128/jb.173.2.697-703.1991

Yuasa, K., Kholidin, E. B., Panigoro, N., \& Hatai, K. (2003). First isolation of Edwardsiella ictaluri from cultured striped catfishPangasius hypophthalmus in Indonesia. Fish Pathology, 38 (4), 181-183. doi:10.3147/jsfp.38.181

\section{Hosted file}

3. Figure edited final 20.10.docx available at https://authorea.com/users/444851/articles/ 544501-the-arrival-establishment-and-spread-of-a-highly-virulent-edwardsiella-ictaluristrain-in-farmed-tilapia-oreochr-omis-spp

\section{Hosted file}

4. Table Fixed final 20.10.docx available at https://authorea.com/users/444851/articles/ 544501-the-arrival-establishment-and-spread-of-a-highly-virulent-edwardsiella-ictaluristrain-in-farmed-tilapia-oreochr-omis-spp 